\title{
Growth and Autolysis of Kluyveromyces Marxianus Stimulated with Lactate Provides Insights into Symbiosis
}

Shou-Chen Lo ( $\nabla$ scl@dragon.nchu.edu.tw)

National Chung Hsing University

Chia-Yin Yang

National Chung Hsing University

Dony Mathew

Washington Senior High School

Chieh-Chen Huang

National Chung Hsing University

\section{Research Article}

Keywords: Kluyveromyces marxianus, yeast , glucose , GAP1, kefir

Posted Date: January 13th, 2021

DOI: https://doi.org/10.21203/rs.3.rs-143082/v1

License: (c) (i) This work is licensed under a Creative Commons Attribution 4.0 International License.

Read Full License

Version of Record: A version of this preprint was published at Scientific Reports on July 15th, 2021. See the published version at https://doi.org/10.1038/s41598-021-94101-y. 


\section{Abstract}

Kluyveromyces marxianus is a yeast that was identified from kefir and can use a broad range of substrates, such as glucose and lactate, as carbon sources. The lactate produced in kefir culture can be a substrate for $K$. marxianus. However, the complexity of the kefir microbiota makes the traits of $K$. marxianus difficult to study. In this research, we focused on $K$. marxianus cultured with lactate as the sole carbon source. The optimal growth and released protein in lactate culture were determined under different $\mathrm{pH}$ conditions, and the LC-MS/MS-identified proteins were associated with the tricarboxylic acid cycle, glycolysis pathway, and cellular stress responses in cells, indicating that autolysis of $K$. marxianus had occurred under the culture conditions. The abundant glyceraldehyde-3-phosphate dehydrogenase (GAP1) was crystallized in the cell-free fraction, and the low transcription level of the GAP1 gene indicated that the protein abundance under autolysis conditions was dependent on protein stability. These results suggest that lactate produced by lactic acid bacteria stimulates the growth and autolysis of $K$. marxianus, releasing proteins and peptides. These findings can be fundamental for $K$. marxianus probiotic and kefir studies in the future.

\section{Introduction}

Kluyveromyces marxianus is frequently isolated from dairy products, such as cheese and kefir. It is consistently detected in certain kefir cultures ${ }^{1}$ and can be acquired from unpasteurized milk ${ }^{2}$. The long history of safe use of these products makes $K$. marxianus a generally recognized as safe (GRAS) yeast strain. In a recent review, K. marxianus was considered as a potential probiotic yeast ${ }^{3}$. K. marxianus can utilize a broad spectrum of carbon sources, including carbohydrates and organic acids, such as glucose, sucrose, lactose, fructose, galactose, xylose, lactic acid and malic acid ${ }^{4}$, making it suitable for use in the food industry. In kefir cultures, lactate can be a nonfermentable carbon source for K. marxianus. However, the complexity of the symbiotic bacteria and yeasts in kefir culture makes the interactivity of the microbiota difficult to study. To simplify the interaction between $K$. marxianus and lactate, we focused on the traits of the $K$. marxianus lactate culture.

Although several nonfermentable carbon sources can be used to grow K. marxianus, protein expression under these culture conditions is rarely discussed. Another issue with using nonfermentable carbon sources as substrates is autolysis. The known autolysis in Saccharomyces cerevisiae occurs after fermentable carbon sources are exhausted at stationary phase in the culture ${ }^{5}$. Substitution of a fermentable carbon source with a nonfermentable carbon source can lead to the formation of a stressful environment for yeast.

Lactate is a nonfermentable carbon source for yeast. It is known that some $S$. cerevisiae strains can express pectinase in the presence of lactate ${ }^{6}$. The induction of secreted pectinase expression implies that lactate can upregulate the expression of certain proteins in $S$. cerevisiae. Furthermore, both $S$. cerevisiae and $K$. marxianus can reduce lactate feedback inhibition of lactic acid bacteria ${ }^{7}$. With lactate as the sole carbon source, $K$. marxianus exhibits potential for biotechnological applications. The lactate 
uptake mechanism of $K$. marxianus involves uptake of lactate anions with a monocarboxylate uniport ${ }^{8}$. Therefore, the lactate uptake efficiency depends on the $\mathrm{pH}$ of the culture medium for the dissociation of lactate. Culture conditions with nonfermentable carbon sources and low pH cause autolysis in $S$. cerevisiae during winemaking ${ }^{5}$. Autolysis of yeast leads to the release of low-molecular-weight compounds and peptides that impart additional flavor or sweetness to the wine ${ }^{5,9}$. In this study, the proteins that were released from $K$. marxianus autolysis and the transcription level of the genes that encoded the high-abundance proteins were investigated. The total released proteins were analyzed by SDS-PAGE and liquid chromatography-tandem mass spectrometry (LC-MS/MS). The results showed that maximum protein release occurred in culture medium at $\mathrm{pH}$ 5.2, and 11 out of the 15 most abundant proteins were possible moonlighting proteins.

\section{Results}

\section{The initial pH value of the lactate culture medium affects the growth of $\mathrm{K}$. marxianus}

The K. marxianus Bot3 +7 strain was cultured in YPD medium for two days as a seed culture. Then, synthetic yeast culture medium with lactate as the sole carbon source, $\mathrm{YNL}$, with different initial $\mathrm{pH}$ values was used for batch cultivation of the $K$. marxianus strain for five days. The growth curves and the released protein concentrations are shown in Fig. 1a, b. Optimal growth was observed at pH 4.18 (optical density at $\left.600 \mathrm{~nm}\left(\mathrm{OD}_{600}\right)=19\right)($ Table 1). Upon cultivation with YNL medium at $\mathrm{pH}$ values higher than 4.8 , the cell concentration of the $K$. marxianus strain decreased (Table 1). This might be because the dissociation of lactate anions decreased with increasing $\mathrm{pH}$ in the medium. 
Table 1

Growth of Kluyveromyces marxianus Bot3 +7 and protein concentrations in different culture media.

\begin{tabular}{|c|c|c|c|}
\hline Medium & Initial OD 600 & $\mathrm{OD}_{600}$ (5 days) & $\begin{array}{l}\text { Protein concentration } \\
\text { ( } \mu \mathrm{g} / \mathrm{mL}, 5 \text { days) }\end{array}$ \\
\hline $\mathrm{YNL}^{\mathrm{a}} \mathrm{pH} 3.9$ & $0.124 \pm 0.006^{c}$ & $15.429 \pm 0.634$ & $59.112 \pm 10.694$ \\
\hline YNL pH 4.18 & $0.583 \pm 0.005$ & $19.008 \pm 0.025$ & $99.394 \pm 10.768$ \\
\hline YNL pH 4.8 & $0.2 \pm 0.0119$ & $5.813 \pm 0.192$ & $101.228 \pm 29.918$ \\
\hline YNL pH 5.2 & $0.172 \pm 0.007$ & $6.864 \pm 1.365$ & $178.528 \pm 50.534$ \\
\hline YNL pH 5.44 & $0.412 \pm 0.002$ & $5.780 \pm 0.020$ & $79.685 \pm 10.011$ \\
\hline YNL pH 6.23 & $0.208 \pm 0.005$ & $1.850 \pm 0.110$ & $75.185 \pm 9.579$ \\
\hline YNL pH $5.44+\mathrm{Mg}^{\mathrm{b}}$ & $0.482 \pm 0.004$ & $8.641 \pm 0.097$ & $22.290 \pm 10.122$ \\
\hline
\end{tabular}

a YNL indicates synthetic medium with $2 \%$ lactic acid as a carbon source.

${ }^{\mathrm{b}} 0.2 \mathrm{M} \mathrm{MgCl}_{2}$ was present in the YNL medium.

${ }^{c}$ The data are expressed as the mean \pm standard deviation; $\mathrm{n}=3$ independent biological samples.

\section{Protein released to the culture medium}

Table 1 shows that the concentration of protein released to the culture medium was associated with the initial $\mathrm{pH}$ of the culture medium. Maximum protein release was observed at pH $5.2\left(178 \mu \mathrm{g} \mathrm{mL}^{-1}\right)$ (Table 1). According to Nambu-Nishida et al.'s report ${ }^{10}$, the divalent metal ion $\mathrm{Mg}^{2+}$ may affect many cellular and biological processes by changing the membrane permeability. In a previous study, the presence of $\mathrm{MgCl}_{2}$ decreased autolysis in S. cerevisiae ${ }^{11}$. Therefore, the presence of $\mathrm{Mg}^{2+}$ ions might help the $K$. marxianus strain grow with lactate and decrease autolysis. In the presence of $0.2 \mathrm{M} \mathrm{MgCl}_{2}$, the final cell concentration $\left(\mathrm{OD}_{600}\right)$ at $\mathrm{pH} 5.44$ increased from 5.78 to 8.64 , and the released protein concentration decreased from $79.6 \mu \mathrm{g} \mathrm{mL}^{-1}$ to $22.2 \mu \mathrm{gL}^{-1}$ (Fig. 1c, d; Table 1).

\section{Culture medium filtrate and protein concentration}

The released protein level in the culture medium was too low for direct analysis by SDS-PAGE or LCMS/MS. The culture media were first filtered with membranes with a molecular weight cutoff of $3 \mathrm{k}$ as described in the methods. The proteins were concentrated 20-fold for SDS-PAGE analysis (Supplementary Fig. S1). However, the amount of protein was not suitable for total protein LC-MS/MS analysis. Therefore, $300 \mathrm{~mL}$ of culture medium (at pH 5.44) in another batch experiment of $K$. marxianus Bot3 +7 was collected to obtain more protein. Approximately $0.1 \mathrm{mg} \mathrm{mL}^{-1}$ protein was obtained on the 12th day of incubation (data not shown). It took more than twice as much time to reach the optimum concentration of released protein than it did with the 3-mL culture (Fig. 1b). The medium was filtered through a 0.2- $\mu \mathrm{m}$ 
pore size membrane and stored at $4{ }^{\circ} \mathrm{C}$ for further concentration and desalting. Noticeable small crystals appeared in the storage medium after 2 days (Fig. 2a). The crystals formed in the culture medium did not dissolve in $\mathrm{dd}_{2} \mathrm{O}$ and methanol but could be dissolved in Bradford reagent and low-pH solutions, such as $10 \%$ acetic acid. The crystals dissolved in Bradford reagent were analyzed by SDS-PAGE, and there were two major bands at approximately $37 \mathrm{kDa}$ and $27 \mathrm{kDa}$ (Fig. 2b). To determine the identity of the proteins, the bands were excised and sent for LC-MS/MS analysis. Peptide fingerprinting of the 37-kDa and 27-kDa proteins identified both proteins as glyceraldehyde 3-phosphate dehydrogenase 1 (GAP1) in K. marxianus (Fig. 3). Some protein regions were unmatched, which might have been due to insufficient in-gel trypsin digestion. Nonetheless, a notable fingerprint peptide (VAVFQEK) was absent just before the second acid cleavage site in the peptide (aspartic acid-proline, 79D-80P) among the 27-kDa peptide fingerprints compared with the 37-kDa fingerprints (Fig. 3; Supplementary Table S1). The molecular mass of the N-terminal peptides (residues 1-79) after acid cleavage of G3P1 was approximately $9 \mathrm{kDa}$. These results suggest that the 27-kDa protein was derived from the acid cleavage of GAP1 when the protein was dissolved in acidic solutions.

\section{General proteomics of released protein from K. marxianus in lactate culture medium}

\section{Analysis of total released protein with LC-MS/MS}

Nonetheless, protein crystals were formed, and the proteins in YNL medium at pH 5.44 were further desalted and concentrated to $10 \mu \mathrm{g} / \mu \mathrm{L}$ for LC-MS/MS analysis as described in the methods. Note that since the samples were released by autolysis, the proteins would be cleaved at unexpected cleavage sites. To maintain reliability of the LC-MS/MS analysis, only trypsin cleavage-derived peptides were used as fingerprints to identify proteins. Therefore, the numbers of matched peptides were lower than expected. However, the identified proteins could be confirmed in the autolysis medium. A total of 513 proteins were matched in the NCBI K. marxianus protein database, and 473 out of the 513 identified proteins could be mapped to UniProtKB for further Gene Ontology (GO) classification.

\section{Metabolism}

Proteins associated with the tricarboxylic acid cycle, gluconeogenesis, and pentose phosphate pathway were identified (Supplementary Table S2). Among other carbohydrate metabolism processes, proteins related to galactose metabolism and exoinulinase were identified (Supplementary Table S2). Two proteins were identified as being related to lactate metabolism (D-lactate dehydrogenase [cytochrome] 2 and cytochrome b2) (Supplementary Table S2).

\section{Stress response}

The identified proteins included 29 proteins that were related to cellular stress responses, such as responses to starvation ( 5 proteins), osmotic stress (8 proteins), and oxidative stress (17). Notably, a 
$12 \mathrm{kDa}$ heat shock protein (HSP12) was related to both osmotic and oxidative stress; therefore, it could be counted as only 1 protein, making the total 29. A total of 13 proteins (including heat shock proteins and chaperones) that help protein folding and refolding were identified in the sample (Supplementary Table S2).

\section{Abundance of identified proteins}

The protein abundance is presented as a percentage of the exponentially modified protein abundance index $(\mathrm{emPAI} \%)^{12}$, and the 15 most abundant proteins (emPAl\% > 0.5) are listed in Table 2 . The major groups of proteins were related to metabolic pathways and the heat shock response. GAP1, enolase (ENO), phosphoglycerate kinase (PGK), phosphoglycerate mutase 1 (GPM1), fructose-bisphosphate aldolase (FBA1) and pyruvate decarboxylase (PDC1) were related to the gluconeogenesis pathway. Heat shock proteins, including HSP12, heat shock protein 26 (HSP26), and heat shock protein SSA3 (SSA3), were associated with the response to stress conditions. The other proteins were triosephosphate isomerase (TPI1), transaldolase (TAL1), alcohol dehydrogenase 2 (ADH2), alcohol dehydrogenase (adh), elongation factor 2 (EFT1) and D-arabinose dehydrogenase [NAD(P)+] heavy chain (ARA1) (Table 2). Since the samples collected were of proteins released by autolysis, the observed proteins were relatively stable under the autolysis conditions. The most abundant protein, HSP12, had a notable abundance ratio compared to all the other matched proteins (Table 2). However, GAP1 crystallized during storage before LC-MS/MS analysis, so the abundance ratio of GAP1 in the total released proteins was underestimated. 
Table 2

The 15 most abundant proteins from LC-MS/MS analysis.

\begin{tabular}{|c|c|c|c|c|c|c|}
\hline $\begin{array}{l}\text { NCBI } \\
\text { accession } \\
\text { number }\end{array}$ & Protein name ${ }^{a}$ & $M_{r}$ & Matches & Sequences & emPAI ${ }^{b}$ & $\begin{array}{l}\text { Moonlighting } \\
\text { protein } \\
\text { references }\end{array}$ \\
\hline BA039229.1 & $\begin{array}{l}12-k D a \text { heat shock } \\
\text { protein }\end{array}$ & 11,193 & $54(52)$ & $10(9)$ & 18.70 & \\
\hline P84998.1 & $\begin{array}{l}\text { Glyceraldehyde-3- } \\
\text { phosphate } \\
\text { dehydrogenase } 1\end{array}$ & 35,231 & $99(90)$ & 20(19) & 3.51 & $22,27,35$ \\
\hline BA038084.1 & Enolase & 46,773 & 128(115) & $20(19)$ & 2.30 & 36 \\
\hline P84998.1 & $\begin{array}{l}\text { Triosephosphate } \\
\text { isomerase }\end{array}$ & 26,979 & $48(45)$ & $15(14)$ & 1.43 & 41 \\
\hline BA038162.1 & $\begin{array}{l}\text { Phosphoglycerate } \\
\text { kinase }\end{array}$ & 44,418 & $84(76)$ & 19(19) & 1.35 & 35 \\
\hline BA039929.1 & Transaldolase & 36,452 & $41(37)$ & $18(18)$ & 1.21 & 36,37 \\
\hline BAP70103.1 & $\begin{array}{l}\text { Phosphoglycerate } \\
\text { mutase } 1\end{array}$ & 27,480 & $44(42)$ & $12(11)$ & 1.16 & 35 \\
\hline BA042678.1 & $\begin{array}{l}\text { Heat shock protein } \\
\text { SSA3 }\end{array}$ & 70,036 & $93(86)$ & $27(26)$ & 0.81 & \\
\hline BA040152.1 & $\begin{array}{l}\text { Heat shock protein } \\
26\end{array}$ & 21,932 & $49(46)$ & $7(7)$ & 0.70 & \\
\hline Q9P4C2.3 & $\begin{array}{l}\text { Alcohol } \\
\text { dehydrogenase } 2\end{array}$ & 36,945 & $42(38)$ & $16(15)$ & 0.67 & 42 \\
\hline BA040412.1 & $\begin{array}{l}\text { Fructose- } \\
\text { bisphosphate } \\
\text { aldolase }\end{array}$ & 39,472 & $57(53)$ & $14(14)$ & 0.62 & 35 \\
\hline QGN17490.1 & $\begin{array}{l}\text { Pyruvate } \\
\text { decarboxylase }\end{array}$ & 61,862 & $68(61)$ & $20(19)$ & 0.60 & 39 \\
\hline CAA42785.1 & $\begin{array}{l}\text { Alcohol } \\
\text { dehydrogenase }\end{array}$ & 41,661 & $55(52)$ & $11(11)$ & 0.59 & 35 \\
\hline BA039040.1 & $\begin{array}{l}\text { Elongation factor } \\
2\end{array}$ & 93,293 & 108(95) & $33(31)$ & 0.56 & 36,38 \\
\hline
\end{tabular}

${ }^{a}$ The moonlighting proteins that were reported either in $K$. marxianus or other species are highlighted in gray.

${ }^{b}$ The emPAI\% is presented as the mean of three replicates. 


\begin{tabular}{|lllllll|}
\hline $\begin{array}{l}\text { NCBI } \\
\text { accession } \\
\text { number }\end{array}$ & Protein name ${ }^{a}$ & $M_{\boldsymbol{r}}$ & Matches & Sequences & emPAI\% $^{b}$ & $\begin{array}{l}\text { Moonlighting } \\
\text { protein } \\
\text { references }\end{array}$ \\
\hline BA039872.1 & $\begin{array}{l}\text { D-arabinose } \\
\text { dehydrogenase } \\
{[\text { NAD(P)+] heavy }} \\
\text { chain }\end{array}$ & 38,883 & $46(43)$ & $13(13)$ & 0.55 & \\
\hline
\end{tabular}

${ }^{a}$ The moonlighting proteins that were reported either in $K$. marxianus or other species are highlighted in gray.

${ }^{b}$ The emPAI\% is presented as the mean of three replicates.

\section{Potential strong promoters under lactate culture conditions}

High abundance of proteins in culture medium may be a result of pH-induced expression, protein stability, or both. To further investigate the transcription levels of the matched protein-encoding genes, the expression of the $H S P 12, G A P 1$, and ENO genes was measured by using quantitative real-time polymerase chain reaction (qPCR) (Fig. 4). In addition, the potential promoters of INU1 and PGU1, which encode inulinase and polygalacturonase, respectively, were also analyzed. The promoter of INU1 was applied for heterologous protein expression ${ }^{13,14}$, and the promoter of PGU1 has potential biotechnological applications in $K$. marxianus ${ }^{15}$. The transcription levels of all the genes were determined by qPCR and compared with that of the actin $(A C T)$ gene to calculate the relative transcription levels. HSP12 presented relatively high transcription levels at pH 3.9 and $\mathrm{pH} 4.8$, and the transcription level decreased at pH 6.23 (Fig. 4). The GAP1 transcription level was lower than that of $A C T$ under all the tested conditions (Fig. 4). ENO transcription was high at pH 3.9 but decreased at pH 4.8 and pH 6.23 (Fig. 4). The notably high transcription levels of $P G U 1$ at every tested $\mathrm{pH}$ indicated the potential for application in heterologous enzyme expression. On the other hand, the transcription levels of INU1 were lower than those of PGU1 (Fig. 4).

\section{Discussion}

K. marxianus produces different secreted enzymes when different carbon sources are used. For example, pectinase is produced when glucose or pectin is used as a carbon source ${ }^{15}$, and inulinase is produced when inulin or sucrose is used as a carbon source ${ }^{16}$. Therefore, it would be interesting to identify the proteins produced by K. marxianus in kefir culture. Lactate is the primary acid that is produced in kefir culture, and its level can range from 0.6 to $1 \%(\mathrm{w} / \mathrm{v})^{17,18}$. On the other hand, application of the lactate assimilation trait of $K$. marxianus was reported to reduce the L-lactate feedback inhibition of Lactococcus lactis for nisin production ${ }^{7}$. This indicates that $K$. marxianus could play the same role during kefir production and the potential of lactate usage for biotechnological applications. In this study, to study microbiota interactions in kefir, we focused on using lactate as the sole carbon source to culture $K$. marxianus. The proteins released from $K$. marxianus under lactate culture conditions were identified. 
DL-lactate was used as the sole carbon substrate for batch cultivation of $K$. marxianus at different $\mathrm{pH}$ values. Even under the optimal growth conditions at $\mathrm{pH} 4.18$, as shown in the results (Table 1), the released protein concentrations and the SDS-PAGE analysis of released protein indicated that some of the yeast cells were still autolyzed (Supplementary Fig. S1). The mechanism of autolysis in K. marxianus is based on the biosynthesis of lytic enzymes, which is similar to the mechanism in S. cerevisiae 19,20, and optimum autolysis was observed at $\mathrm{pH} 4.5$ in culture ${ }^{20}$. In this study, the optimum culture $\mathrm{pH}$ for autolysis was observed to be $\mathrm{pH} 5.2$ (Table 1). However, the culture conditions were different from those in this study ${ }^{20}$, since this work lacked fermentable carbon sources in the culture medium. In the presence of $0.2 \mathrm{M} \mathrm{MgCl}_{2}$, the final cell concentrations and the released protein concentrations in the culture medium increased and decreased, respectively (Fig. 1c, d). The presence of excess $\mathrm{Mg}^{2+}$ ions facilitates protein secretion in $K$. marxianus $\left(0.2 \mathrm{M} \mathrm{MgSO}_{4}\right){ }^{10}$ and decreases autolysis in marine bacteria $(0.5 \mathrm{M}$ $\left.\mathrm{MgCl}_{2}\right)$ and $S$. cerevisiae $\left(0.1 \% \mathrm{MgCl}_{2}\right)^{11,21}$. Although the mechanism remains unclear, it was proposed that $\mathrm{Mg}^{2+}$ ions might help organize cell membranes in both eukaryotes and prokaryotes ${ }^{10}$. The GAP1 and HSP12 proteins found in the culture filtrate were also related to the maintenance of cell membrane integrity and stability 22,23 . These results suggest that $K$. marxianus may bear the stress that could decompose membranes. Nonetheless, the inhibition of autolysis suggested that the presence of $0.2 \mathrm{M}$ $\mathrm{MgCl}_{2}$ helped $K$. marxianus resist the stress occurring under the lactate culture conditions (Fig. 1c, d).

GAP1 is a moonlighting (multifunctional) protein that is involved in glycolysis and constitutively expressed when fermentable or nonfermentable carbon sources are used ${ }^{24}$. Some glyceraldehyde 3phosphate dehydrogenases are related to aggregation and apoptosis ${ }^{25,26}$. However, GAP1 was reported to be related to flocculation and contributes to cell wall integrity in $K$. marxianus ${ }^{22,27}$. The expression of GAP1 from K. marxianus in S. cerevisiae induces flocculation ${ }^{27}$. In this study, even though the yeast was separated from the proteins, stable GAP1 crystallized in the liquid (Fig. 2a). These results indicate that GAP1 plays an important role in $K$. marxianus flocculation.

LC-MS/MS analysis of the total protein content revealed the identities of the proteins released after autolysis, other than the crystallized GAP1, and it also provided a glimpse of the metabolic pathways in K. marxianus. Enzymes in central metabolic pathways, such as the tricarboxylic acid cycle, glycolysis/gluconeogenesis, and pentose phosphate pathway, were identified (Supplementary Table S2). Although DL-lactate was the only carbon source that was supplied to the culture medium, proteins related to galactose and inulin metabolism were also expressed (Supplementary Table S2). These results suggest that $K$. marxianus has the potential to assimilate galactose and inulin under these culture conditions. Two lactate metabolism-related proteins, namely, D-lactate dehydrogenase [cytochrome] 2 and cytochrome b2, were identified (Supplementary Table S2). D-lactate dehydrogenase [cytochrome] 2 catalyzes the conversion of D-lactate to pyruvate with the reduction of two molecules of cytochrome. The association between these identified lactate assimilation proteins and the expression of the central metabolism enzymes indicates the lactate assimilation pathway in $K$. marxianus. It was reported that the PGU1 promoter is activated in the presence of lactate in $S$. cerevisiae ${ }^{6}$. In the lactate culture of $K$. 
marxianus, the transcription levels of PGU1 were higher than those of GAP1 and INU1 (Fig. 4). However, none of the analyzed peptides matched the PGU1 protein in our results. Among the 15 most abundant proteins, the average emPAI\% of HSP12 was $18.7 \%$, and that of the second abundant protein, GAP1, was $3.51 \%$ (Table 2). There was a $15.19 \%$ difference between these two proteins, and the third most abundant protein differed from GAP1 by only $1.21 \%$ (Table 2 ). These results suggest that most of the proteins were digested to unidentified peptides under the autolysis conditions. Therefore, PGU1 might be digested to unidentified peptides. However, none of the peptides matched PGU1, even though no enzyme digest fingerprints were considered (data not shown), which needs to be further investigated.

GAP1 was crystallized in the cell-free fraction and was found to be the second most abundant protein in the results (Table 2). However, the transcription level of GAP1 was lower than that of $A C T$ (Fig. 4). These results suggest that the protein abundance in the autolysis condition was dependent on the stability of the protein, not on the gene transcription level. The most abundant protein, HSP12, was reported to increase membrane stability under different stress conditions in $S$. cerevisiae, such as heat shock and oxidative and osmotic stresses ${ }^{23}$. The expression of HSP12 in S. cerevisiae may also contribute to lifespan extension by protecting the membrane from desiccation ${ }^{28,29}$. The relatively high expression of HSP12 (Fig. 4) under the autolysis conditions suggests that HSP12 might play a similar role in protecting K. marxianus cells. Additionally, Marchal, et al. ${ }^{30}$ demonstrated the contribution of peptides from HSP12 of $S$. cerevisiae to sweet perception after yeast autolysis in wine. HSP12 from K. marxianus autolysis might also contribute additional flavor in kefir culture.

Protein abundance was related to protein stability and to $K$. marxianus abundance under the autolysis conditions. However, one cannot exclude the possibility that proteins might also be secreted into the medium rather than released from dead yeast cells. For example, GAP1, enolase and pyruvate decarboxylase are secreted into the extracellular space in Candida albicans without N-terminal signal peptides ${ }^{31}$. These nonconventional protein secretion pathways were also found in S. cerevisiae ${ }^{32}$ and are related to nonclassical export (NCE) genes ${ }^{33}$ such as NCE102, which is also encoded in the $K$. marxianus genome ${ }^{34}$. Although 513 proteins were identified, only 15 proteins had an abundance ratio higher than $0.5 \%$ (Table 2). Additionally, the 11 out of 15 most abundant proteins (Table 2) were reported as moonlighting proteins that do not have $\mathrm{N}$-terminal signal peptides and might be secreted by nonconventional protein secretion pathways ${ }^{35-42}$. The alternative functions of these moonlighting proteins were reported to bind plasminogen, extracellular matrix protein (fibronectin, vitronectin and laminin) and kininogen and inhibit transcription ${ }^{35-39,41,42}$. Most of these studies focused on the extracellular matrix protein binding activities of these moonlighting proteins on the cell surface of the opportunistic pathogenic yeasts $C$. albicans, Candida parapsilosis and Candida tropicalis. Considering that the moonlighting proteins in this study were identified from the cell-free fraction, the alternative functions of these proteins might be different from those in previous reports. However, this could imply that the moonlighting proteins released from $K$. marxianus possibly competitively bind to extracellular matrix proteins and reduce the ability of those pathogenic yeasts to adhere to the cell surface. On the other hand, the secreted proteins might also be digested into peptides as the rest of the proteins are 
released by autolysis and become substrates for other symbiotic-related proteins in kefir. The well-known symbiotic interaction between Lactobacillus bulgaricus and Streptococcus thermophilus in yogurt is that S. thermophilus produces formate to stimulate L. bulgaricus, and L. bulgaricus liberates free amino acids and peptides from milk proteins to stimulate $S$. thermophilus ${ }^{43}$. In this study, lactate was used as a substrate for $K$. marxianus to grow and induce autolysis of $K$. marxianus to release proteins and peptides into the cell-free fraction. This suggests that the lactate produced by lactic acid bacteria would stimulate $K$. marxianus to release proteins and peptides. However, the functions of those proteins and peptides remain to be discovered. The proposed interaction model of lactic acid bacteria and $K$. marxianus is presented in Fig. 5. Nonetheless, the potential of K. marxianus lactate culture for preventing pathogenic yeast invasion and the roles of the released proteins and peptides in kefir culture need further investigation in the future.

K. marxianus has received recognition for its potential industrial applications in recent years due to its thermotolerance, rapid growth rates, and broad substrate spectrum ${ }^{4}$. Although knowledge of its biochemistry and genetics is limited compared to that for $S$. cerevisiae, many studies based on different biochemical principles, such as nonhomologous end joining ${ }^{44}$, homologous recombination ${ }^{45,46}$, and the CRISPR/Cas9 mechanism ${ }^{47}$, have been applied to develop genetic engineering tools. These studies used fermentable substrates for culture, such as glucose and galactose. Therefore, knowledge on culturing nonfermentable substrates is limited. In this study, the optimal lactate culture conditions, the released proteins and the transcription levels of several genes were determined in $K$. marxianus. Autolysis occurred in all of the experimental lactate culture conditions, and the LC-MS/MS results that present various heat shock proteins and moonlighting proteins can be the foundation of $K$. marxianus probiotic and kefir research.

\section{Materials And Methods}

\section{Yeast strain and culture conditions}

The K. marxianus Bot $3+7$ strain was first precultured for two days at $30^{\circ} \mathrm{C}$ with rotation at $120 \mathrm{rpm}$ in YPD medium containing $10 \mathrm{~g}$ of yeast extract, $20 \mathrm{~g}$ of peptone, and $20 \mathrm{~g}$ of glucose per liter of distilled water. To measure growth and protein release, precultured cells from a two-day culture were diluted 1:100 by adding $30 \mu \mathrm{L}$ of the suspension to $3 \mathrm{~mL}$ of $\mathrm{YNL}$ medium (a synthetic medium composed of $6.7 \mathrm{~g}$ of yeast nitrogen-base without amino acids (Difco, Detroit, MI, USA) and $20 \mathrm{~g}$ of lactic acid (J.T. Baker, Philipsburg, NJ, USA) per liter of distilled water). The pH of the YNL medium was adjusted to 3.9, 4.18, $4.8,5.2,5.44$ or 6.23 , followed by the addition of $\mathrm{NaOH}$ (Showa, Tokyo, Japan). All yeast cultures were incubated at $30^{\circ} \mathrm{C}$ in a rotating incubator $(120 \mathrm{rpm})$. The medium was supplemented with $\mathrm{MgCl}_{2}$ as indicated in the manuscript. For LC-MS/MS analysis of the total protein content, the precultured cells were diluted by adding $3 \mathrm{~mL}$ of the suspension to $300 \mathrm{~mL}$ of YNL medium (pH 5.44) and incubated at $30^{\circ} \mathrm{C}$ in a shaking incubator (120 rpm) for LC-MS/MS protein analysis.

\section{Growth curves and protein concentration determination}


The growth of the K. marxianus Bot3 +7 strain was determined by measuring the $\mathrm{OD}_{600}$ and $\mathrm{OD}_{595}$ with a GeneQuant 1300 system (GE Healthcare, Little Chalfont, Buckinghamshire, UK) and a Tecan Sunrise Basic microplate reader (Tecan Austria $\mathrm{GmbH}$, Grödig, Austria), respectively. At each time point during the 5-day cultivation period, $20 \mu \mathrm{L}$ of yeast culture was sampled and aliquoted into a 96-well microplate in triplicate and diluted $1: 10$ by adding $180 \mu \mathrm{L}$ of distilled water to measure the growth. Additionally, protein secretion into the external medium was determined by measuring the $\mathrm{OD}_{595}$ with a Tecan Sunrise Basic microplate reader using the Bradford method with bovine serum albumin as the standard by following the manufacturer's instructions (Bio-Rad Protein Assay Dye Reagent, Bio-Rad, Hercules, CA, USA). For this, 50 $\mu \mathrm{L}$ of yeast culture at each time point was centrifuged at 14,000 rpm for $3 \mathrm{~min}$. After centrifugation, $40 \mu \mathrm{L}$ of supernatant was sampled into a 96-well microplate in triplicate, and $160 \mu \mathrm{L}$ of Bradford reagent (1.25fold) was added to be diluted 5 -fold with the protein.

\section{SDS-PAGE}

The crystals were collected into $1.5-\mathrm{mL}$ centrifuge tubes with pipet tips and washed with $\mathrm{ddH}_{2} \mathrm{O}$. Then, the crystals were added and dissolved into Bradford reagent solutions until saturation. Ten microliters of sample and prestained protein marker (PageRuler Plus Prestained Protein Ladder, 10 to $250 \mathrm{kDa}$, Thermo Scientific) were used for SDS-PAGE analysis.

\section{Sample preparation for LC-MS/MS protein analysis Proteins in the SDS-PAGE gel}

The protein bands were first excised as small pieces from the gel. Then, $25 \mathrm{mM}$ ammonium bicarbonate (ABC, Fluka) (dissolved in 50\% acetonitrile (ACN, J.T. Baker, Philipsburg, NJ, USA)) was added. The mixture was incubated for $30 \mathrm{~min}$ at room temperature, which was repeated if the gel pieces were not destained. Dehydration was performed by the addition of $100 \%$ ACN. Reduction and alkylation were performed with the following steps: $10 \mathrm{mM}$ dithiothreitol (DTT, Sigma) (dissolved in $50 \mathrm{mM} \mathrm{ABC}$ ) was added to the gel pieces, followed by incubation for $60 \mathrm{~min}$ at $56^{\circ} \mathrm{C}$. The solutions were discarded, $55 \mathrm{mM}$ iodoacetamide (IAA, dissolved in $50 \mathrm{mM} \mathrm{ABC;}$;igma) was added, and the gel pieces were incubated for $45 \mathrm{~min}$ in the dark at room temperature. The solutions were discarded, and the gel pieces were dehydrated with $100 \%$ ACN. Trypsin $(12.5 \mathrm{ng} / \mu \mathrm{L}$, dissolved in $50 \mathrm{mM} \mathrm{ABC;}$;rypsin Gold, Promega) was added to the gel pieces, which were rehydrated at $4{ }^{\circ} \mathrm{C}$ for $30 \sim 60 \mathrm{~min}$ and then digested overnight at $37^{\circ} \mathrm{C}$. To recover the peptides from the gel, first, $30 \sim 100 \mu \mathrm{L}$ of $5 \%$ formic acid (FA, dissolved in $50 \% \mathrm{ACN}$; Fluka) was added, and the gel pieces were agitated at room temperature for 30-60 min and transferred to a new centrifuge tube. Second, $15 \sim 50 \mu \mathrm{L}$ of $5 \% \mathrm{FA}$ was added, and the tube was incubated at room temperature for $10 \mathrm{~min}$, followed by the addition of $15 \sim 50 \mu \mathrm{L}$ of $100 \% \mathrm{ACN}$ and agitation for 30-60 min. Third, the two extract solutions were combined and dried in a Speed Vac. The samples were desalted using C18 ZipTips (Millipore) with the following steps: the dried peptide mixtures were desalted in $10 \mu \mathrm{L}$ of $\mathrm{ddH}_{2} \mathrm{O}$ containing $0.1 \%$ FA, a ZipTip was activated by rinsing 3 times with $10 \mu \mathrm{L}$ of $100 \%$ ACN, the tip 
was equilibrated 3 times with $10 \mu \mathrm{L}$ of $0.1 \% \mathrm{FA}$, peptides were bound to the tip by aspirating and dispensing the peptide solutions 10 times, the tip was washed 6 times with $10 \mu \mathrm{L}$ of $0.1 \% \mathrm{FA}$, and peptides were eluted with $10 \mu \mathrm{L}$ of $0.1 \%$ FA (dissolved in $50 \%$ ACN) by aspirating and dispensing 10 times. These steps were repeated to obtain a combined solution, and the combined solution was dried with a SpeedVac vacuum concentrator.

\section{Proteins in autolysis medium}

The proteins in the supernatant of the 12-day $K$. marxianus culture were concentrated to $10 \mu \mathrm{g} / \mu \mathrm{L}$ using Amicon Ultra-15 $3 \mathrm{k}$ molecular weight cutoff membranes (Millipore) according to the manufacturer's instructions. The samples were also dialyzed $3.7 \times 10^{-15}$ times with $50 \mathrm{mM}$ Tris- $\mathrm{HCl}(\mathrm{pH} \mathrm{8.03)}$. Then, $1 \mu \mathrm{L}$ of DTT (1 M) and $2.5 \mu \mathrm{L}$ of $10 \%$ SDS were added to $20 \mu \mathrm{L}$ of the sample, and cooled to room temperature after incubation for $10 \mathrm{~min}$ at $95^{\circ} \mathrm{C}$. Three microliters of $1 \mathrm{M}$ IAA was added, and the samples were reacted for $30 \mathrm{~min}$ in the dark at room temperature. Twelve microliters of $40 \%$ acrylamide, $4.5 \mu \mathrm{L}$ of $10 \%$ SDS, $1.5 \mu \mathrm{L}$ of $10 \%$ APS and $0.5 \mu \mathrm{L}$ of TEMED were added, and the samples were incubated for $30 \mathrm{~min}$ at room temperature to form a tube gel. The solutions were discarded, and $500 \mu \mathrm{L}$ of $\mathrm{ddH}_{2} \mathrm{O}$ was added. Then, the gel was incubated for $30 \mathrm{~min}$ at room temperature and cut into small pieces. The small pieces were washed three times. First, $100 \mathrm{mM} \mathrm{ABC}$ was used for $15 \mathrm{~min}$. Then, $50 \mathrm{mM} \mathrm{ABC}$ and $50 \%$ ACN were used for $30 \mathrm{~min}$, followed by washing with $100 \%$ ACN for $10 \mathrm{~min}$. After washing, the samples were dried with a SpeedVac vacuum concentrator. Trypsin $(0.5 \mu \mathrm{g})$ was added, and the samples were digested at $37^{\circ} \mathrm{C}$ for 16 hours. ACN $(100 \%)$ was added to the peptide extract and reacted for $30 \mathrm{~min}$ at room temperature, and then, the supernatant was transferred to a new tube. ACN $(50 \%)$ and FA (1\%) were added, and the samples were incubated for $60 \mathrm{~min}$ at room temperature. Then, the supernatant was transferred to a new tube. Subsequently, $100 \%$ ACN was added, and the samples were incubated for $10 \mathrm{~min}$ at room temperature. Then, the supernatant was transferred to a new tube. The supernatant was dried with a SpeedVac vacuum concentrator and resuspended in $20 \mu \mathrm{L}$ of $0.1 \% \mathrm{FA}$ (in $\mathrm{ddH}_{2} \mathrm{O}$ ). The samples were desalted and concentrated using C18 ZipTip as mentioned previously. The samples were then resuspended in $50 \mu \mathrm{L}$ of $0.1 \% \mathrm{FA}$ (in $\mathrm{ddH}_{2} \mathrm{O}$ ).

\section{LC-MS/MS protein analysis}

LC-MS/MS analysis was performed on an UltiMate 3000 RSLCnano LC system (Thermo Fisher Scientific) coupled with a TripleTOF® 6600 mass spectrometer (Applied Biosystems Sciex) equipped with information-dependent acquisition (IDA) mode and an electrospray ionization (ESI) source operating in positive mode.

\section{Protein identification}

The proteins in the SDS-PAGE gel were identified by using the following methods. The liquid chromatography conditions were as follows: separation of eluted peptides was performed on an Acclaim PepMap C18 analytical column (75 $\mu$ I.D. x 25 cm nanoViper, $2 \mu \mathrm{m}$ particle size, $100 \AA ̊$ pore size, Thermo Fisher Scientific). Mobile phase A was $0.1 \% \mathrm{FA}$ in $\mathrm{ddH}_{2} \mathrm{O}$, and mobile phase $\mathrm{B}$ was $0.1 \% \mathrm{FA}$ in 
$100 \%$ ACN. The gradient was as follows: 0-4.5 min 95\% A, 4.5-31 min $95-65 \%$ A, 31-32 min $65-10 \% A$, 32-52 $\mathrm{min} 10 \% \mathrm{~A}, 52-53 \mathrm{~min} 10-95 \% \mathrm{~A}$, and $53-70 \mathrm{~min} 95 \% \mathrm{~A}$. The flow rate was $300 \mathrm{~nL} / \mathrm{min}$ at $35{ }^{\circ} \mathrm{C}$, and the sample loading volume was $10 \mu \mathrm{L}(0.1 \% \mathrm{FA})$. The samples were examined in triplicate.

The mass spectrometric conditions were as follows: The operating parameters of ESI mode were utilized: ion spray voltage $+2,500 \mathrm{~V}$, interface heater temperature $150^{\circ} \mathrm{C}$, declustering potential $80 \mathrm{~V}$ and column oven temperature $35^{\circ} \mathrm{C}$. The sheath gas and curtain gas were both nitrogen, and the pressures were 15 and $30 \mathrm{psi}$, respectively. The IDA mode was utilized. The TOF-MS scan range was set to $350 \sim 1250 \mathrm{~m} / \mathrm{z}$ acclimated for $0.25 \mathrm{sec}$, and the MS/MS scan range was set to $65 \sim 1,800 \mathrm{~m} / \mathrm{z}$ acclimated for $0.1 \mathrm{sec}$. Rolling collision energy voltage was used. The top 20 parent ions were selected following MS/MS. Mascot (version 2.3.02) was used to search the database.

\section{Proteomics Identifications (PRIDE)}

The released proteins were identified by the methods described above. Under LC conditions, the gradient was as follows: 0-4.5 min 95\% A, 4.5-95 min 95-70\% A, 95-101 min 70 - 40\% A, 101-106 min 40$10 \% A, 106-131 \min 10 \% A, 131-132 \min 10-95 \% A$, and $132-150 \min 95 \% A$. The flow rate was $300 \mathrm{~nL} / \mathrm{min}$ at $35^{\circ} \mathrm{C}$, and the sample loading volume was $10 \mu \mathrm{L}(0.1 \% \mathrm{FA})$.

The mass spectrometric conditions were as follows: The operating parameters of ESI mode were utilized: ion spray voltage $+2,800 \mathrm{~V}$, interface heater temperature $150^{\circ} \mathrm{C}$, declustering potential $80 \mathrm{~V}$, column oven temperature $35^{\circ} \mathrm{C}$. The sheath gas and curtain gas were both nitrogen, and the pressures were 15 and 30 psi, respectively. The IDA mode was utilized. The TOF-MS scan range was set to $350 \sim 1,250 \mathrm{~m} / \mathrm{z}$ acclimated for $0.25 \mathrm{sec}$, and the MS/MS scan range was set to $65 \sim 1,800 \mathrm{~m} / \mathrm{z}$ acclimated for $0.1 \mathrm{sec}$. Rolling collision energy voltage was used. The top 20 parent ions were selected following MS/MS. Mascot (version 2.3.02) was used to search the database.

\section{Mascot search parameters}

The type of search and enzyme were set as MS/MS Ion Search and trypsin, respectively. The variable modifications included carbamidomethyl (C), deamidated (NQ), oxidation (HW), and oxidation (M). Monoisotopic was used as the mass parameter, and the mass tolerance values for peptides and fragments were $\pm 0.05 \mathrm{Da}$ and $\pm 0.03 \mathrm{Da}$, respectively. The max missed cleavages by enzyme was set as 2. The database used for the search was the NCBI K. marxianus database. The results are provided as a Supplementary Dataset.

\section{Quantitative real time polymerase chain reaction procedure}

Total RNA extraction was performed using TRIzol Reagent (Invitrogen). The yeast cells were collected by centrifugation, and then, the total RNA was extracted according to the manufacturer's instructions. The RNA yield was determined by a Nano-100 Micro-Spectrophotometer (Medclub Scientific Co., Ltd., Taiwan). A total of $0.1 \mu \mathrm{g}$ of RNA was converted to cDNA using the GoScript ${ }^{\text {TM }}$ Reverse Transcription System, and qPCR analysis was performed using LightCycler 480 SYBR Green Master Mix (Roche) on a Rotor-Gene 3000 Real-Time DNA Detection System (Corbett Research). The transcription levels were 
calculated for reverse transcriptase-treated and nontreated samples and normalized to those of actin $(A C T)$. The changes in relative transcription levels were calculated as fold changes using the $\triangle \triangle C t$ method. All the primers used for analysis in this study are listed in Supplementary Table S3.

\section{Declarations}

\section{Data Availability}

All data generated or analysed during this study are included in this published article (and its Supplementary Information files).

\section{Acknowledgment}

We thank Ms. Chen Hui-Yi for technical support with LC-MS/MS analysis. The image in Fig. 2a was taken with an iPhone 6 (Apple) through a microscope (Nikon) by S.C.L., and then, the image was edited by Adobe Photoshop 2020 by C.Y.Y. The image in Fig. 2b was taken by an iPhone 6 (Apple) by S.C.L., and then, the image was edited by Microsoft Office Professional 2019 PowerPoint by C.Y.Y. The illustration in Fig. 5 was drawn with Microsoft Paint 3D by C.Y.Y. This work was supported by the Ministry of Science and Technology [107-2621-M-005-007-MY3 to C.C.H. and 108-2811-M-005-526- to S.C.L.].

\section{Author contributions}

S.C.L. conceived the experiments, S.C.L. and C.Y.Y. conducted the experiments, and S.C.L., C.Y.Y., D.C.M., and C.C.H. analyzed the results and wrote and reviewed the manuscript.

\section{Additional information}

\section{Competing interests}

The authors declare no competing interest.

\section{References}

1. Simova, E. et al. Lactic acid bacteria and yeasts in kefir grains and kefir made from them. J. Ind. Microbiol. Biotechnol. 28, 1-6, doi:10.1038/sj/jim/7000186 (2002).

2. Karkowska-Kuleta, J., Satala, D., Bochenska, O., Rapala-Kozik, M. \& Kozik, A. Moonlighting proteins are variably exposed at the cell surfaces of Candida glabrata, Candida parapsilosis and Candida 
tropicalis under certain growth conditions. BMC Microbiol. 19, 149 https://doi.org/10.1186/s12866019-1524-5 (2019).

3. Kinnby, B., Booth, N. A. \& Svensäter, G. Plasminogen binding by oral streptococci from dental plaque and inflammatory lesions. Microbiology (Reading). 154, 924-931 https://doi.org/10.1099/mic.0.2007/013235-0 (2008).

4. Yang, W., Li, E., Kairong, T. \& Stanley, S. L. Jr. Entamoeba histolytica has an alcohol dehydrogenase homologous to the multifunctional adhE gene product of Escherichia coli. Mol. Biochem. Parasitol. 64, 253-260 https://doi.org/10.1016/0166-6851(93)00020-a (1994).

5. Driessen, F. M., Kingma, F. \& Stadhouders, J. Evidence that Lactobacillus bulgaricus in yogurt is stimulated bu carbon dioxide produced by Streptococcus thermophilus. v. 36 (1982).

6. Hoshida, H. et al. Non-homologous end joining-mediated functional marker selection for DNA cloning in the yeast Kluyveromyces marxianus. Yeast. 31, 29-46 https://doi.org/10.1002/yea.2993 (2014).

7. Chang, J. J. et al. A synthetic biology tool for engineering a cellulolytic yeast. Biotechnology for Biofuels 5. PGASO, 53 https://doi.org/10.1186/1754-6834-5-53 (2012).

8. Nambu-Nishida, Y., Nishida, K., Hasunuma, T. \& Kondo, A. Development of a comprehensive set of tools for genome engineering in a cold- and thermo-tolerant Kluyveromyces marxianus yeast strain. Sci. Rep. 7, 8993-8993 https://doi.org/10.1038/s41598-017-08356-5 (2017).

9. Rajkumar, A. S., Varela, J. A., Juergens, H., Daran, J. M. G. \& Morrissey, J. P. Biological parts for Kluyveromyces marxianus synthetic biology. Frontiers in Bioengineering and Biotechnology. 7 , https://doi.org/10.3389/fbioe.2019.00097 (2019).

10. Nambu-Nishida, Y., Nishida, K., Hasunuma, T. \& Kondo, A. Genetic and physiological basis for antibody production by Kluyveromyces marxianus. AMB Express 8, 56-56, doi:10.1186/s13568-0180588-1 (2018).

11. Dabija, A. \& Sion, I. in SIPA' 03 51-56 (Orizonturi Universitare, Timisoara, Romania, 2003).

12. Ishihama, Y. et al. Exponentially modified protein abundance index (emPAl) for estimation of absolute protein amount in proteomics by the number of sequenced peptides per protein. Mol. Cell. Proteomics 4, 1265-1272, doi:10.1074/mcp.M500061-MCP200 (2005).

13. Bergkamp, R. J. et al. Expression of an alpha-galactosidase gene under control of the homologous inulinase promoter in Kluyveromyces marxianus. Appl. Microbiol. Biotechnol. 40, 309-317, doi:10.1007/bf00170386 (1993).

14. Rocha, S. N., Abrahão-Neto, J., Cerdán, M. E., Gombert, A. K. \& González-Siso, M. I. Heterologous expression of a thermophilic esterase in Kluyveromyces yeasts. Appl. Microbiol. Biotechnol. 89, 375385, doi:10.1007/s00253-010-2869-8 (2011).

15. Piemolini-Barreto, L. T., AntÔnio, R. V. \& Echeverrigaray, S. Screening and breeding of Kluyveromyces strains for production pectinolytic activity. Adv Biotech \& Micro. 3, 555608, doi:10.19080/AIBM.2017.03.555608 (2017).

16. da Silva, E. G., Borges, M. d. F., Medina, C., Piccoli, R. H. \& Schwan, R. F. Pectinolytic enzymes secreted by yeasts from tropical fruits. FEMS Yeast Res. 5, 859-865, 
doi:10.1016/j.femsyr.2005.02.006 (2005).

17. Guzel-Seydim, Z., Seydim, A. C. \& Greene, A. K. Organic acids and volatile flavor components evolved during refrigerated storage of kefir. J. Dairy Sci. 83, 275-277, doi:10.3168/jds.S0022-0302(00)748740 (2000).

18. Özdestan, Ö. \& Üren, A. Biogenic amine content of kefir: a fermented dairy product. Eur. Food Res. Technol. 231, 101-107, doi:10.1007/s00217-010-1258-y (2010).

19. Amrane, A. \& Prigent, Y. Behaviour of the yeast Kluyveromyces marxianus var. marxianus during its autolysis. Antonie Van Leeuwenhoek 69, 267-272, doi:10.1007/BF00399615 (1996).

20. Amrane, A. \& Prigent, Y. Effect of culture conditions of Kluyveromyces marxianus on its autolysis, and process optimization. Bioprocess Eng. 18, 383-388, doi:10.1007/PL00008998 (1998).

21. Sugahara, I., Hayashi, K., Kimura, T. \& Jinno, C. Studies on marine bacteria producing lytic enzymes IX: Effect of inorganic salts on the autolysis of bacterial cells Capable of Producing Lytic Enzyme. (1983).

22. Falcão Moreira, R., Fernandes, P. A. \& Moradas-Ferreira, P. Kluyveromyces marxianus flocculence and growth at high temperature is dependent on the presence of the protein p37. Microbiology 144, 681688, doi:https://doi.org/10.1099/00221287-144-3-681 (1998).

23. Welker, S. et al. Hsp12 is an intrinsically unstructured stress protein that folds upon membrane association and modulates membrane function. Mol. Cel/ 39, 507-520, doi:https://doi.org/10.1016/j.molcel.2010.08.001 (2010).

24. Fernandes, P. A., Sena-Esteves, M. \& Moradas-Ferreira, P. Characterization of the glyceraldehyde-3phosphate dehydrogenase gene family from Kluyveromyces marxianus-polymerase chain reactionsingle-strand conformation polymorphism as a tool for the study of multigenic families. Yeast 11, 725-733, doi:10.1002/yea.320110804 (1995).

25. Itakura, M. et al. Glyceraldehyde-3-phosphate dehydrogenase aggregates accelerate amyloid- $\beta$ amyloidogenesis in Alzheimer disease. J. Biol. Chem. 290, 26072-26087, doi:10.1074/jbc.M115.669291 (2015).

26. Silva, A. et al. Glyceraldehyde-3-phosphate dehydrogenase (GAPDH) is a specific substrate of yeast metacaspase. Biochim. Biophys. Acta 1813, 2044-2049, doi:https://doi.org/10.1016/j.bbamcr.2011.09.010 (2011).

27. Moreira, R. F., Ferreira-da-Silva, F., Fernandes, P. A. \& Moradas-Ferreira, P. Flocculation of Saccharomyces cerevisiae is induced by transformation with the GAP1 gene from Kluyveromyces marxianus. Yeast 16, 231-240, doi:10.1002/(sici)1097-0061(200002)16:3<231::aid-yea530>3.0.co;2c (2000).

28. Herbert, A. P. et al. NMR structure of Hsp12, a protein induced by and required for dietary restrictioninduced lifespan extension in yeast. PLoS One 7, e41975, doi:10.1371/journal.pone.0041975 (2012).

29. Singarapu, K. K. et al. Structural characterization of Hsp12, the heat shock protein from Saccharomyces cerevisiae, in aqueous solution where it is intrinsically disordered and in detergent 
micelles where it is locally a-helical. J. Biol. Chem. 286, 43447-43453, doi:10.1074/jbc.M111.306464 (2011).

30. Marchal, A., Marullo, P., Moine, V. \& Dubourdieu, D. Influence of yeast macromolecules on sweetness in dry wines: role of the saccharomyces cerevisiae protein Hsp12. J. Agric. Food Chem. 59, 20042010, doi:10.1021/jf103710x (2011).

31. Gil-Bona, A. et al. Proteomics unravels extracellular vesicles as carriers of classical cytoplasmic proteins in Candida albicans. Journal of Proteome Research 14, 142-153, doi:10.1021/pr5007944 (2015).

32. Kuchler, K. Unusual routes of protein secretion: the easy way out. Trends Cell Biol. 3, 421-426, doi:10.1016/0962-8924(93)90030-5 (1993).

33. Nombela, C., Gil, C. \& Chaffin, W. L. Non-conventional protein secretionin yeast. Trends Microbiol. 14, 15-21, doi:https://doi.org/10.1016/j.tim.2005.11.009 (2006).

34. Lertwattanasakul, N. et al. Genetic basis of the highly efficient yeast Kluyveromyces marxianus: complete genome sequence and transcriptome analyses. Biotechnology for Biofuels 8, 47, doi:10.1186/s13068-015-0227-x (2015).

35. Crowe, J. D. et al. Candida albicans binds human plasminogen: identification of eight plasminogenbinding proteins. Mol. Microbiol. 47, 1637-1651, doi:10.1046/j.1365-2958.2003.03390.x (2003).

36. Kozik, A. et al. Fibronectin-, vitronectin- and laminin-binding proteins at the cell walls of Candida parapsilosis and Candida tropicalis pathogenic yeasts. BMC Microbiol. 15, 197, doi:10.1186/s12866015-0531-4 (2015).

37. Karkowska-Kuleta, J. et al. Characterization of the interactions between human high-molecular-mass kininogen and cell wall proteins of pathogenic yeasts Candida tropicalis. Acta Biochim. Pol. 63, 427436, doi:10.18388/abp.2016_1353 (2016).

38. Karkowska-Kuleta, J. et al. Molecular determinants of the interaction between human high molecular weight kininogen and Candida albicans cell wall: Identification of kininogen-binding proteins on fungal cell wall and mapping the cell wall-binding regions on kininogen molecule. Peptides 32, 2488-2496, doi:10.1016/j.peptides.2011.10.021 (2011).

39. Destruelle, M., Menghini, R., Frontali, L. \& Bianchi, M. M. Regulation of the expression of the Kluyveromyces lactis PDC1 gene: carbon source-responsive elements and autoregulation. Yeast 15, 361-370, doi:10.1002/(sici)1097-0061(19990330)15:5<361::Aid-yea378>3.0.Co;2-3 (1999).

40. Karkowska-Kuleta, J., Satala, D., Bochenska, O., Rapala-Kozik, M. \& Kozik, A. Moonlighting proteins are variably exposed at the cell surfaces of Candida glabrata, Candida parapsilosis and Candida tropicalis under certain growth conditions. BMC Microbiol. 19, 149, doi:10.1186/s12866-019-1524-5 (2019).

41. Kinnby, B., Booth, N. A. \& Svensäter, G. Plasminogen binding by oral streptococci from dental plaque and inflammatory lesions. Microbiology (Reading) 154, 924-931, doi:10.1099/mic.0.2007/013235-0 (2008). 
42. Yang, W., Li, E., Kairong, T. \& Stanley, S. L., Jr. Entamoeba histolytica has an alcohol dehydrogenase homologous to the multifunctional adhE gene product of Escherichia coli. Mol. Biochem. Parasitol. 64, 253-260, doi:10.1016/0166-6851(93)00020-a (1994).

43. Driessen, F. M., Kingma, F. \& Stadhouders, J. Evidence that Lactobacillus bulgaricus in yogurt is stimulated bu carbon dioxide produced by Streptococcus thermophilus. v. 36 (1982).

44. Hoshida, H. et al. Non-homologous end joining-mediated functional marker selection for DNA cloning in the yeast Kluyveromyces marxianus. Yeast 31, 29-46, doi:10.1002/yea.2993 (2014).

45. Chang, J.-J. et al. PGASO: A synthetic biology tool for engineering a cellulolytic yeast. Biotechnology for Biofuels 5, 53, doi:10.1186/1754-6834-5-53 (2012).

46. Nambu-Nishida, Y., Nishida, K., Hasunuma, T. \& Kondo, A. Development of a comprehensive set of tools for genome engineering in a cold- and thermo-tolerant Kluyveromyces marxianus yeast strain. Sci. Rep. 7, 8993-8993, doi:10.1038/s41598-017-08356-5 (2017).

47. Rajkumar, A. S., Varela, J. A., Juergens, H., Daran, J.-M. G. \& Morrissey, J. P. Biological parts for Kluyveromyces marxianus synthetic biology. Frontiers in Bioengineering and Biotechnology 7 , doi:10.3389/fbioe.2019.00097 (2019).

\section{Figures}




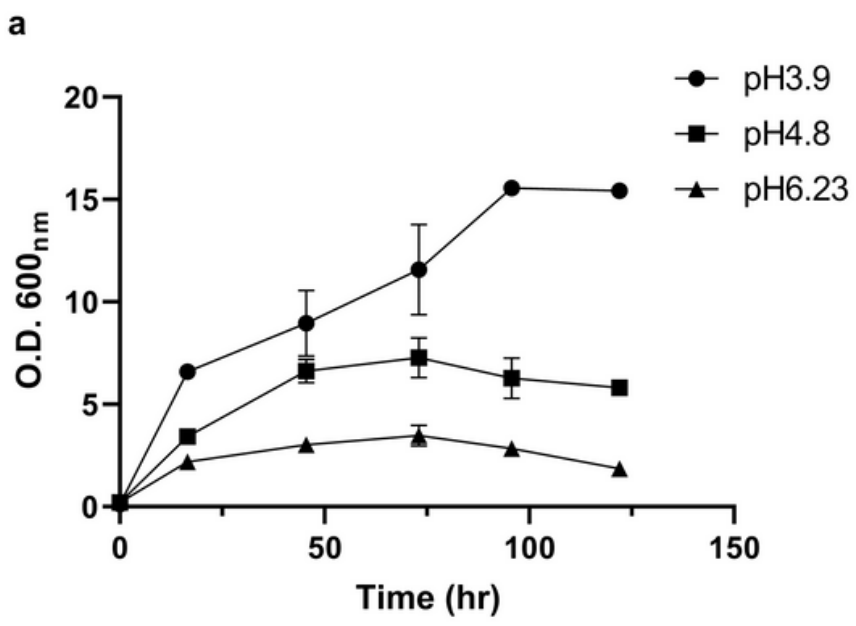

b
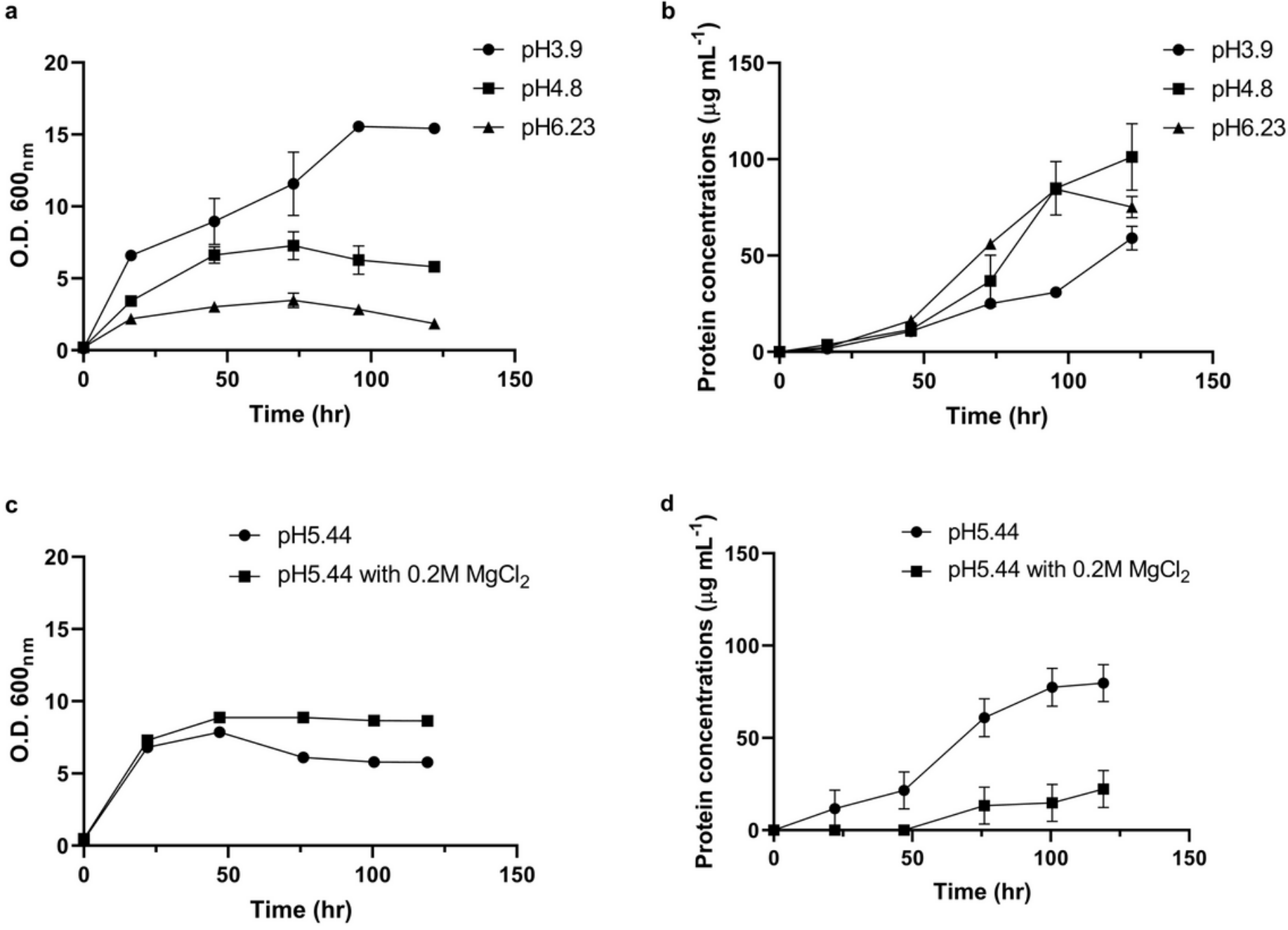

Figure 1

Growth curves and released protein concentrations of $\mathrm{K}$. marxianus strain Bot $3+7$ at different $\mathrm{pH}$ values or with $\mathrm{Mg}$ supplementation. (a) Growth curve of $\mathrm{K}$. marxianus strain Bot3+7 at pH 3.9, $\mathrm{pH} 4.8$, and pH 6.23. (b) Released protein concentration of K. marxianus strain Bot3 +7 at $\mathrm{pH} 3.9, \mathrm{pH} 4.8$, and pH 6.23. (c) Growth curve of K. marxianus strain Bot3+7 at pH 5.44 in the presence or absence of $0.2 \mathrm{M} \mathrm{MgCl}$. (d) Released protein concentration of K. marxianus strain Bot $3+7$ at pH 5.44 in the presence or absence of $0.2 \mathrm{M} \mathrm{MgCl} 2$. 
a

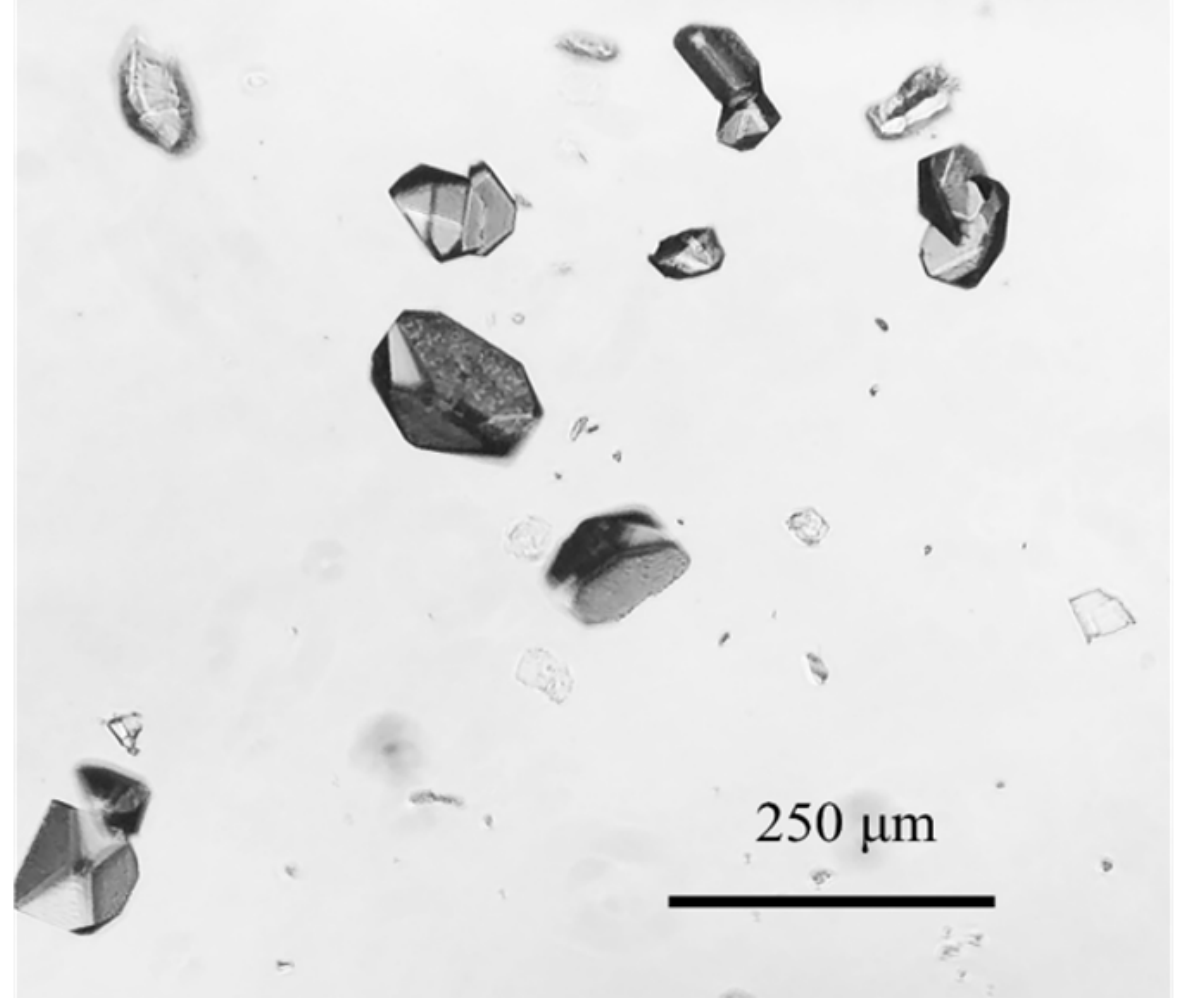

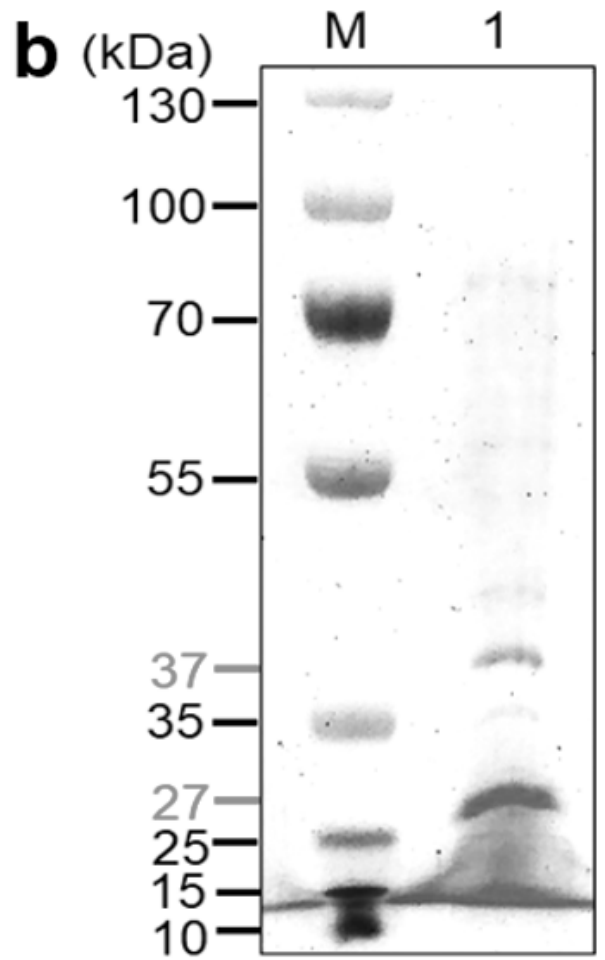

Figure 2

Microscopic photograph and SDS-PAGE analysis of protein crystals from the YNL culture filtrate at pH 5.44. (a) Microscopic photograph of the protein crystals. (b) SDS-PAGE analysis of the YNL culture filtrate at $\mathrm{pH}$ 5.44. Lanes $\mathrm{M}$ and 1 indicate the protein ladder and protein crystals, respectively.

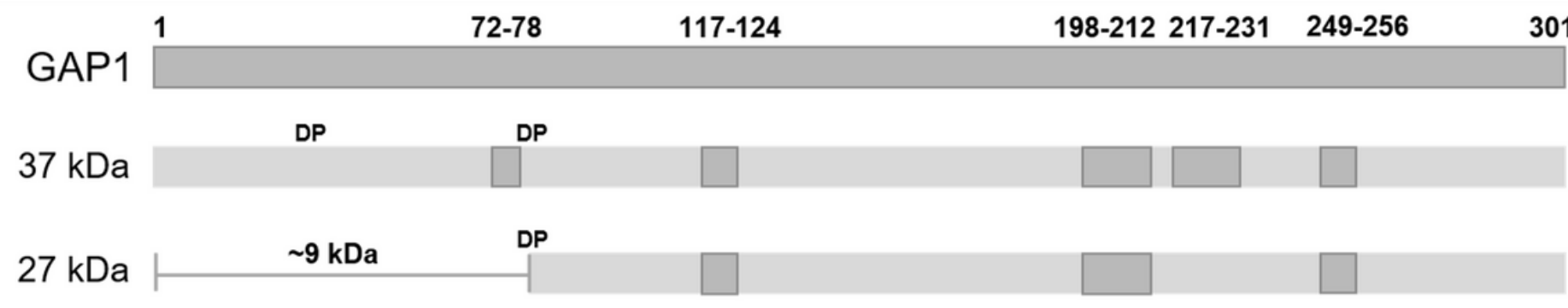

\section{Figure 3}

Schematic diagram of the peptides that matched to glyceraldehyde-3-phosphate dehydrogenase (GAP1) from the 37-kDa and 27-kDa protein bands in SDS-PAGE analysis. 




Figure 4

Relative transcription levels of HSP12, GAP1, ENO, PGU1, and INU1 compared with those of ACT at pH $3.9, \mathrm{pH} 4.8$, and $\mathrm{pH} 6.23$ in culture. The data are presented as the mean and standard deviation of three replicates. 


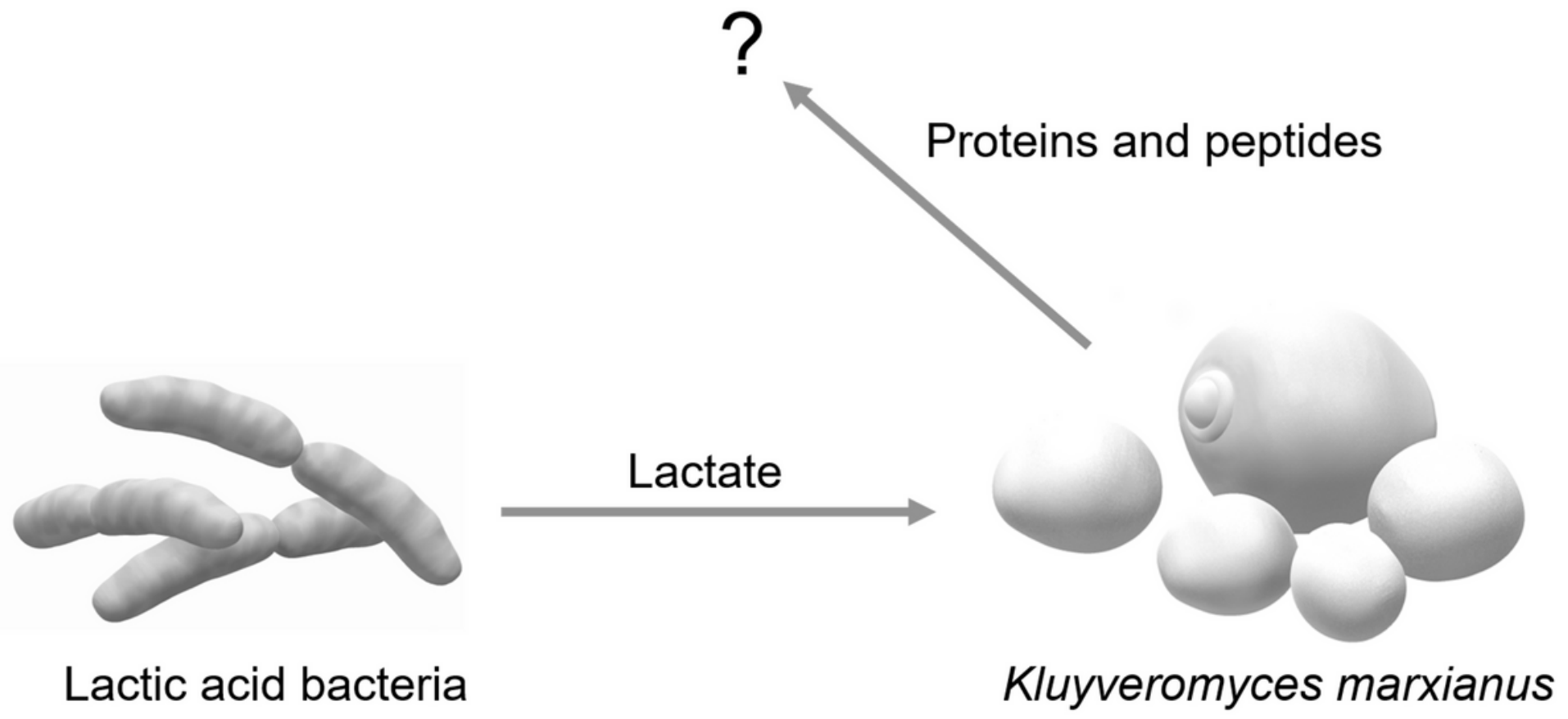

Figure 5

Schematic diagram of the proposed interaction between lactic acid bacteria and K. marxianus.

\section{Supplementary Files}

This is a list of supplementary files associated with this preprint. Click to download.

- SupplementaryDatasetYNLpercolator.xlsx

- SupplementaryInformationFig.S1TableS1S2S3.docx 